\title{
AS DIFICULDADES DA PESSOA COM TRANSTORNO DE DÉFICIT DE ATENÇÃO NA VIDA ADULTA
}

\section{ARTIGO DE REVISÃO}

LIMA, Isadora dos Reis ${ }^{1}$

LIMA, Isadora dos Reis. As dificuldades da pessoa com Transtorno de Déficit de Atenção na vida adulta. Revista Científica Multidisciplinar Núcleo do Conhecimento. Ano 04, Ed. 07, Vol. 08, pp. 05-12. Julho de 2019. ISSN: 2448-0959

\section{RESUMO}

O presente artigo irá discorrer sobre o Transtorno do Déficit de Atenção - TDA na vida adulta. Seu objetivo é identificar as dificuldades encontradas por um adulto com TDA, assim como analisar quais são essas dificuldades e buscar melhorias na qualidade de vida para este adulto. Este artigo refere-se a uma pesquisa bibliográfica fundamentada nos conceitos teóricos de Silva (2008), Arruda (2006) e Barkley e Benton (2011) sobre suas respectivas teorias do adulto com esse transtorno.

Palavras-Chave: Transtorno de Déficit de Atenção, TDA em adultos, dificuldade do adulto com TDA.

\section{INTRODUÇÃO}

O Transtorno de Déficit de Atenção ou também conhecido por Distúrbio de Déficit de Atenção pode ou não estar ligado à hiperatividade e impulsividade. Apesar do subtipo combinado desse transtorno ser deveras comum, encontra-se assim a apresentação do mesmo quando é predominantemente do tipo desatento. Attention Deficit Disorder é o termo que originou o nome do transtorno em português. "Disorder" pode ser

1 Graduada em Licenciatura Plena em Pedagogia pela Universidade Paulista, Especialista em Educação Especial e Inclusiva pela Faculdade de Teologia e Ciências Humanas. 
entendido por desordem, transtorno ou distúrbio, por este motivo há essas denominações do transtorno, mas equivalem ao mesmo déficit.

Esse artigo será dissertado a partir da problemática sobre quais são as dificuldades que uma pessoa com o Transtorno de Déficit de Atenção possui na vida adulta. Muitas vezes o adulto com esse transtorno transparece a figura de uma pessoa "preguiçosa" ou "desleixada", quando na verdade e muito pelo contrário não são só necessariamente características pessoais, mas sim uma patologia clínica descrita pela Associação Americana de Psiquiatria.

O objetivo deste é identificar as dificuldades encontradas por um TDA na vida adulta, bem como analisar quais são essas dificuldades e buscar melhorias para que uma pessoa com o TDA possa conviver sem grandes prejuízos na vida educacional, familiar, afetiva e social. Esta será uma pesquisa bibliográfica onde serão usados livros e artigos de internet para sua fundamentação. Este trabalho será embasado nas fundamentações teóricas de Silva (2008), mais precisamente no seu livro "Mentes Inquietas" que discorre sobre a temática de pessoas com o Transtorno do Déficit de Atenção com ou sem hiperatividade. Será fundamentado também das inferências de Arruda (2006) e Barkley e Benton (2011) a cerca desse transtorno em adultos. O DSMV auxiliará como base para os conceitos médicos descritos pela Associação Americana de Psiquiatria.

À vista disso, às consequências funcionais para o adulto com TDA ou TDAH estão associadas ao mau desempenho escolar e acadêmico, conflito interpessoal em relações afetivas e o desemprego. Para que este adulto usufrua com maestria de suas funções familiares e sociais é necessário que o mesmo compreenda sobre seus sintomas, seja diagnosticado e tratado por um médico especialista.

\section{HISTÓRICO}

Segundo a Associação Brasileira do Déficit de Atenção, o TDA é caracterizado como "um transtorno neurobiológico, de causas genéticas, que aparece na infância e frequentemente acompanha o indivíduo por toda a sua vida. Ele se caracteriza por 
sintomas de desatenção, inquietude e impulsividade. Ele é chamado às vezes de TDA". O TDA é também um transtorno crônico que se manifesta e evolui ao longo da vida e suas manifestações são na maioria das vezes em crianças persistindo até a vida adulta.

Arruda (2006, p. 9) diz que o "TDA é um transtorno multifatorial, pois, são vários fatores envolvidos na sua gênese, desde a genética, hemorragias, adversidades físicas durante a gestação, até mesmo eventos agressores ao cérebro na infância", ou seja, não se pode afirmar que apenas um fator contribui para o desenvolvimento do TDA.

O contexto histórico do Transtorno de Déficit de Atenção (TDA) está diretamente relacionado com o transtorno de déficit de atenção e Hiperatividade (TDAH). Em 1902 um pediatra britânico chamado George Fredrick Still, produziu uma série de palestras no qual mencionou sobre vários comportamentos de algumas crianças, as quais eram agressivas, resistentes à disciplina, dificultosas a manter a atenção e o autocontrole. O médico descreveu e caracterizou como defeito maior e crônico no "controle moral". Ele percebeu também as questões hereditárias quanto aos familiares que apresentavam sinais e sintomas de depressão, alterações de conduta ou alcoolismo. Posteriormente, cerca de 20 anos depois, alguns médicos americanos estudaram crianças com características semelhantes às relatadas por George Kill, mas eram crianças sobreviventes de uma inflamação chamada encefalite e a partir de então foram feitos diversos estudos relacionados ao "distúrbio de comportamento pósencefalite". (SILVA, 2008)

Em 1968, no DSM-III o termo usado na Associação de Psiquiatria Americana foi "Reação Hipercinética da Infância". Atualmente, segundo a Associação Americana de Psiquiatria no DSM-V (2014, p14) com especificação no código F90 traz a nomenclatura de "Transtorno de Déficit de Atenção/Hiperatividade" e no código F90.0 indica o subtipo "Apresentação Predominantemente Desatenta".

Em 1957 a expressão "hiperatividade infantil" foi usada por Laufer e em 1960 por Stella Chess. Laufer acreditava que esta síndrome era particular do sexo masculino, já 
Chess, considerava os sintomas como hiperatividade fisiológica, e as causas seriam em razão da genética e do meio ambiente, e a partir disso surgiu o termo "síndrome da criança hiperativa". Na década de 1970 o centro dos estudos começou a mudar de hiperatividade para os pontos atentivos graças a teoria de Virginia Douglas que apresentou um raciocínio que dizia que $o$

déficit em suster a atenção poderia manifestar-se em circunstâncias onde não houvesse hiperatividade, Douglas ampliou o conceito dessa definição inclusive dando mais ênfase ao déficit de atenção. Gabriel Weiss, em 1976 apontou através de estudos que ao entrar na adolescência a hiperatividade pode diminuir, mas os problemas de atenção podem continuar. (SILVA, 2008)

O conceito de Weiss fazia ser entendido que a síndrome era algo que "acabaria" com a chegada da adolescência, ou seja, só crianças poderiam ter essa síndrome. Mas, em 1980 foi reconhecida na forma adulta e a Associação Americana de Psiquiatria (AAP) trouxe algumas mudanças, como a renomeação da síndrome para Distúrbio do Déficit de Atenção (DDA).

Em 1994, a Associação Americana de Psiquiatria publicou o DSM-IV. Nessa atualização, o Distúrbio do Deficit de Atenção foi renomeado para transtorno do deficit de atenção/hiperatividade (TDAH) e dividido em três subtipos básicos:

- Tipo predominantemente desatento: quando os sintomas de desatenção são mais marcantes;

- Tipo predominantemente hiperativo/impulsivo: quando os sintomas de hiperatividade e impulsividade estão presentes em proporções significativas e equivalentes;

- Tipo combinado: quando os sintomas de desatenção e de hiperatividade/impulsividade estão presentes no mesmo grau de intensidade. (SILVA, 2008, p. 164) 
Desta forma, pode-se relatar que existem os tipos combinados e os tipos isolados. Os sintomas do TDA e TDAH são fortemente hereditários em torno de $76 \%$. Para a Associação Americana de Psiquiatria (2014, p.106), o fator hereditário é substancial, e afirma também que, "uma minoria de casos pode estar relacionada a reações a aspectos da dieta. Pode haver história de abuso infantil, negligência, múltiplos lares adotivos, exposição à neurotoxina (p. ex., chumbo), infecções (p. ex., encefalite) ou exposição ao álcool no útero". Desta forma, é constatado que o cuidado da mãe na gestação é um fator influenciador direto no desenvolvimento ou não do transtorno.

\section{DIFICULDADES DE UM TDA NA VIDA ADULTA}

São inúmeras as dificuldades que uma pessoa que possui o Transtorno de Déficit de Atenção encontra na vida adulta, a começar pelos aspectos familiares e afetivos até chegar aos aspectos sociais como o trabalho, educação e o convívio social. Para $O$ The Blokehead (2015), cerca de 60\% das crianças com TDA na infância permanecem com os sintomas até a vida adulta.

Com o crescimento da criança para a adolescência e posteriormente para a vida adulta faz-se demonstrar mais evidente a desatenção, pois, aquela criança que antes era apenas "hiperativa ou desatenta" hoje é um adulto que precisa desempenhar papeis importantes na vida familiar ou social. Vale ressaltar que a predominância nos adultos quanto às características do TDA é a desatenção, entretanto também há casos com hiperatividade ou do subtipo combinado.

\section{VIDA EDUCACIONAL}

Na maioria das vezes a desatenção é sutil, na infância não é tão visível como na forma adulta. No âmbito escolar ela pode ser vista através do baixo rendimento, do indivíduo disperso ou esquecido.

Estudantes com TDAH frequentemente não conseguem entender o funcionamento da sala de aula, ou seja, determinar o que é importante e focar sua atenção para essa tarefa. Eles são facilmente distraídos pelos 
colegas ou barulhos fora da sala. (ROTTA, OHLWEILER, RIESGO. 2006, p. 372)

A formação educacional de um sujeito com Transtorno de Déficit de Atenção é deveras complexa visto que afeta diretamente o desempenho acadêmico, o potencial e consequentemente limita a futura escolha de um trabalho. Uma minoria de pessoas com este transtorno também possuem o transtorno de aprendizagem que é caracterizado por um atraso em uma área específica de aprendizagem, como leitura ou escrita. Os dados mostram que $71 \%$ dos adultos diagnosticados na infância foram suspensos ou expulsos da escola pelo menos uma vez. (BARKLEY; BENTON, 2011)

Fonseca (1995, p. 254) diz que: "a atenção compreende uma organização interna e externa de estímulos, organização essa indispensável à aprendizagem, caso contrário às mensagens sensoriais são recebidas, mas não integradas.". Desse modo, a capacidade de se concentrar em algo é de grande importância para que o indivíduo com déficit de atenção possa progredir nos aspectos educacionais. Fonseca (1995, p. 265) também evidencia que a pessoa emocionalmente desajustada é mais propensa a obter resultados escolares ruins, pois, os distúrbios emocionais fragmentam o comportamento e por consequência a capacidade da aprendizagem.

\section{VIDA AFETIVA E FAMILIAR}

Esta dificuldade está ligada aos aspectos afetivos e familiares de um adulto com TDA, pois, são afetados pela dificuldade de concentração ou dificuldade de atenção. A complexidade de se manter concentrado com este transtorno na vida adulta acaba se tornando um obstáculo para o sujeito dentro da sua vida pessoal o que diz respeito a afetividade.

Para Barkley e Benton (2011, p. 198) dizem que a maneira como esse transtorno organiza as coisas contra a pessoa pode impactar mais em sua vida pessoal e social do que em qualquer outro setor da vida, entretanto, com o autocontrole, estímulo e tratamento correto o adulto pode conviver sem muitos prejuízos nesse âmbito. 
Dois dos sintomas mais comuns da pessoa com Transtorno de Déficit de Atenção é estar distraído em conversas de rotina e parecer não escutar quando alguém the dirige a palavra. Para algumas pessoas que se relacionam com pessoas com TDA pode parecer arrogância, desinteresse ou falta de educação. Adultos com déficit de atenção não tem noção da sua condição, mas compreendem sobre os sintomas, que obstaculizam o cumprimento das funções diárias. (THE BLOKEHEAD, 2015)

O controle emocional é substancial e imprescindível para um adulto com TDA, pois, quando predominantemente hiperativo/impulsivo ou subtipo combinado, o indivíduo que possui esse transtorno é mais propenso a falar demais, a não deixar com que as pessoas concluam a frase, a responderem antes de serem perguntados, a interromperem ou se intrometerem em conversas alheias, etc. Diante disso, é necessário que o sujeito tenha controle emocional, saiba esperar e tenha paciência para possa se expressar da forma correta fazendo assim que não haja maiores problemas.

\section{VIDA SOCIAL E TRABALHO}

Entre os adultos, as grandes perturbações referem-se ao ciclo social e ao exercício profissional. São notáveis as dificuldades em se manter focado, organizado e dispor de planejamentos de longo prazo. É perceptível traços de instabilidade emocional em adultos com esse transtorno e também a baixa estima e pouca motivação para engajar-se em atividades.

Para um adulto TDA, manter-se concentrado em algo, por menor tempo que seja, pode ser um desafio tão grande como para um atleta de corrida com obstáculos que precisa transpor barreiras cada vez maiores até chegar ao fim da pista. Essa dificuldade em se manter concentrado em determinado assunto, pensamento, ação ou fala, muitas vezes, causa situações bastante desconfortáveis ao adulto TDA. (SILVA, 2008, p. 14) 
A interferência no funcionamento social pode causar grandes prejuízos. $O$ adulto com TDA tem que se esforçar mais do que o habitual para atingir e manter a atenção necessária

para realizar suas atividades comuns, desta forma, Silva (2008, p. 15) afirma que “alguns usam a expressão 'cansaço na alma' para descrever seu estado após a realização de tarefas nas quais se forçaram em permanecer concentrados por obrigação". À vista disso, pode-se pressupor que manter a concentração para uma pessoa com esse transtorno é demasiadamente fatigante.

Adultos com Transtorno de Déficit de Atenção podem ficar profundamente insatisfeitos com atividades inacabadas, tornando-se deprimidos e com baixa autoestima. Esses são aqueles que não conseguem permanecer no emprego, que tem dificuldade de priorizar atividades importantes de ofício ou as procrastinam. (THE BLOKEHEAD, 2015)

Para Barkley e Benton (2011, p. 178), "se o seu TDAH inclui hiperatividade, é pouco provável que um emprego que requeira que permaneça sentado em uma cadeira na frente de um computador o dia inteiro seja o ideal pra você". Por essa razão é necessário que o adulto com TDA com ou sem predominância em hiperatividade procure empregos onde ele possa se adaptar mais facilmente, um emprego onde haja o máximo de elementos facilitadores e favoráveis para pessoas com esse transtorno, evitando assim frustraçoes e situações constrangedoras. Portanto, Silva (2008, p. 205) diz que é de extrema importância que o TDA saiba que é TDA, pois, conhecer o próprio comportamento é fundamental para que se obtenha êxito no que se faz.

\section{COMORBIDADES}

O sujeito com TDA enfrenta ao longo da vida diferentes dificuldades, uma delas é a comorbidade. Comorbidade é a união de duas ou mais doenças ou transtornos que se apresentam simultaneamente em um determinado indivíduo. Pessoas com TDA podem ou não desenvolver comorbidade. Para Fiore (2007, p. 28): "acumulam ainda uma série de interferências no desenvolvimento educacional, social e futuramente no 
profissional, pois esses sintomas são somatórios e estão intrinsecamente interligados.”. Isto é, podem desenvolver também doenças psicossomáticas.

A Associação Americana de Psiquiatria (2014, p. 109) expõe:

Transtorno explosivo intermitente ocorre em uma minoria de adultos com TDAH, embora com taxas acima dos níveis populacionais. Ainda que transtornos por abuso de substância sejam relativamente mais frequentes entre adultos com TDAH na população em geral, estão presentes em apenas uma minoria deles. Nos adultos, transtorno da personalidade antissocial e outros transtornos da personalidade podem ser comórbidos com TDAH. Outros transtornos que podem ser comórbidos com o TDAH incluem o transtorno obsessivo-compulsivo, os transtornos de tique e o transtorno do espectro autista.

Consoante com Arruda (2006, p. 10): "adultos com TDAH quando comparados com adultos sem este transtorno apresentam mais frequentemente: uso e dependência de drogas, divórcio, tentativa de suicídio, insatisfação profissional e desajuste social”. E em concordância as inferências da Associação Brasileira do Déficit de Atenção podese afirmar que "estudos informam que cerca de $75 \%$ dos adultos com TDAH apresentam mais de uma comorbidade, entre as mais comuns, depressão, ansiedade, compulsão alimentar, distúrbios do sono, drogadição, alcoolismo e dislexia."

Tais comorbidades influenciam nas características e diagnóstico. O insucesso em coisas do cotidiano como afazeres de casa, cuidados com os filhos, casamento e lembretes diários podem ocasionar as comorbidades acima citadas. Consequentemente, a pessoa que adquire comorbidades precisa passar por um tratamento médico diferenciado.

\section{CONCLUSÃO}

O primeiro passo para evitar malefícios na vida de um adulto com Transtorno de Déficit de Atenção é o diagnóstico prévio. Diagnóstico na infância é sinônimo de tratamento 
precoce. Diante disto, em seu ciclo vital o sujeito irá passar por tratamentos e na vida adulta poderá desenvolver estratégias para compreender como lidar com o seu TDA.

A atividade com uma pessoa com o transtorno no âmbito educacional está relacionada a criatividade. Seja na escola ou na vida acadêmica, o professor deverá estimular o que o TDA tem em abundancia: a criatividade. Com base nisso, o professor ou psicopedagogo deverá exercer sua função de mediador e elaborar novas estratégias de aprendizagem, principalmente se este indivíduo possui a comorbidade do TDA/H + Transtorno de Aprendizagem. Portanto, a ideia que um TDA não consegue aprender é uma ideia errônea, pois há mentes brilhantes com déficit de atenção, mentes as quais foram estimuladas por professores, familiares e equipes médicas desde seu diagnóstico prévio.

$\mathrm{Na}$ vida familiar e afetiva $\mathrm{o}$ adulto com déficit de atenção deverá ser estimulado para desenvolver seu autocontrole e sua organização, assim estabelecendo regras e limites para interagir com seus familiares, cônjuge e filhos sem que qualquer infortúnio aconteça.

No convívio social e/ou trabalho, o individuo com esse transtorno deverá exercer seu autodomínio para que possa executar perfeitamente suas atribuições no emprego. É necessário também que o ambiente de trabalho não proporcione ruídos ou distrações em excesso.

Acredita-se que estudos sobre o Transtorno de Déficit de Atenção e as dificuldades que uma pessoa que possui esse transtorno na vida adulta possa gerar novas oportunidades para que todos possam conhecer este déficit e assim poder contribuir para uma melhor inserção do TDA na sociedade. Para saber lidar com um adulto que possui esse transtorno é necessário que o familiar ou amigo procure saber seus sintomas, suas características e quais são os métodos para auxiliar na melhoria da convivência no meio social. Portanto, vale ressaltar que é necessário que o adulto assuma o TDA, pois quanto mais ágil o diagnóstico, melhor o tratamento e consequentemente melhor a qualidade de via. 


\section{REFERÊNCIAS}

ARRUDA, Marco. Levados da Breca: Um guia sobre crianças e adolescentes com o Transtorno do Déficit de Atenção e Hiperatividade (TDAH). 1 Ed. Instituto Glia, 2006.

ASSOCIAÇÃO BRASILEIRA DO DÉFICIT DE ATENÇÃO. Disponível em:http://tdah.org.br/. Acesso em: 5 mar. 2018, 18:46

ASSOCIATION, American Psichiatric. Manual diagnóstico e estatístico de transtornos mentais: DSM-5. 5. Ed. Porto Alegre. Artmed: 2014.

BARKLEY, Russel A.; BENTON, Christine M.. Vencendo o TDAH Adulto: Transtorno de Déficit de Atenção/Hiperatividade.1 Ed. Artmed. 2011.

FIORE, Ana Cristina Leite Ferraz. O transtorno de déficit de atenção e hiperatividade em comorbidade com o fracasso escolar. Dissertação de Mestrado - Centro Universitário Salesiano de São Paulo. São Paulo, p. 28. 2007.

FONSECA, Vitor da. Introdução às Dificuldades de Aprendizagem. 2 ed. rev. Aum . Porto Alegre: Artes Médicas, 1995.

THE BLOKEHEAD. TDAH em adultos: Reconhecer e lidar com adultos que sofrem de TDAH em 30 passos simples. Babelcube Inc. 2015. Disponível em: https://ler.amazon.com.br/?asin=B00ZSZX81A. Acesso em: 15 mar. 2018, 17:02.

ROTTA, Newra Tellechea; OHLWEILER, Lygia; RIESGO, Rudimar dos Santos. Transtorno da Aprendizagem, Abordagem Neurobiológica e Multidisciplinar. Porto Alegre. Artmed. 2006

SILVA, Ana Beatriz Barbosa. Mentes Inquietas: TDAH, Desatenção, Hiperatividade e Impulsividade. Rio de Janeiro: Objetiva. 2008.

Enviado: Março, 2018. 
Aprovado: Julho, 2019. 